\title{
Electrospark deposition of tungsten carbide powder on titanium alloy Ti6Al4V
}

\author{
A. A. Burkov ${ }^{\dagger, 1}$, M. A. Kulik¹, V.O. Krutikova ${ }^{2}$ \\ †burkovalex@mail.ru \\ ${ }^{1}$ Institute of Materials Science, Khabarovsk Scientific Center, FEB RAS, Khabarovsk, 680042, Russia \\ ${ }^{2}$ Yu. A. Kosygin Institute of Tectonics and Geophysics, FEB RAS, Khabarovsk, 680000, Russia
}

Titanium alloys are attracting the attention of researchers and engineers because of their unique combination of high specific strength, corrosion resistance and biocompatibility, but they are characterized by high wear. Therefore, the study of new methods for making protective coatings on titanium alloys is relevant. A mixture of titanium granules with tungsten carbide powder was used to prepare coatings on the titanium alloy Ti6Al4V by the method of electrospark granules deposition. Three mixtures of granules with a tungsten carbide content of 2.1, 4.1 and 6.0 vol.\% were prepared. According to the data of $\mathrm{X}$-ray analysis, it was found that the following phases were observed in the composition of the coatings: $\mathrm{WC}, \mathrm{W}_{2} \mathrm{C}, \mathrm{W}, \mathrm{aTi}^{\mathrm{T}}$ and $\beta-(\mathrm{W}, \mathrm{Ti}) \mathrm{C}_{1-x}$. Carbides $\mathrm{W}_{2} \mathrm{C},(\mathrm{W}, \mathrm{Ti}) \mathrm{C}_{1-x}$ and metallic tungsten were formed as a result of the decarburization of $\mathrm{WC}$ upon its interaction with molten titanium under the conditions of an electric discharge. Large inclusions of tungsten carbide surrounded by a metallic Ti-W-C binder were observed in the microstructure of the coatings. According to the data of energy dispersive analysis, the concentrations of tungsten and carbon decreased when scanning from the surface layers of the coating to the substrate. The average values of the microhardness of the coatings increased from 7.9 to $9.2 \mathrm{GPa}$ with an increase in the concentration of WC powder in the mixture of granules. The average values of the friction coefficients of the coatings were in the range of $0.33-0.48$, which is $35 \pm 3 \%$ lower than that of the Ti6Al4V alloy. Tests for wear in the dry friction mode at loads of 25 and $70 \mathrm{~N}$ showed that the wear rate of the coatings ranged from $0.38 \times 10^{-5}$ to $1.68 \times 10^{-5} \mathrm{~mm}^{3} / \mathrm{Nm}$. The best wear resistance under both loads was demonstrated by the coatings deposited with the addition of 4.1 vol.\% WC, which make it possible to increase the wear resistance of the Ti6Al4V alloy up to 18 times. Thus, the prospect of electrospark deposition of cermet coatings with enhanced mechanical properties on a titanium alloy using tungsten carbide powder mixed with titanium granules is shown.

Keywords: Ti6Al4V alloy, tungsten carbide, electrospark granules deposition, wear resistance, oxidation resistance.

УДК: $621.762 ; 537.523 .4$

\section{Электроискровое нанесение порошка карбида вольфрама на титановый сплав Ti6Al4V}

\author{
Бурков А.А. ${ }^{\dagger, 1}$, Кулик М. А. ${ }^{1}$, Крутикова В. О. ${ }^{2}$ \\ ${ }^{1}$ Институт материаловедения Хабаровского НЦ ДВО РАН, Хабаровск, 680042, Россия \\ ${ }^{2}$ Институт тектоники и геофизики им. Ю.А. Косыгина ДВО РАН, Хабаровск, 680000, Россия
}

Титановые сплавы привлекают внимание исследователей и инженеров из-за уникального сочетания высокой удельной прочности, коррозионной устойчивости и биосовместимости, однако они характеризуются высоким износом. Поэтому изучение новых методов создания защитных покрытий на титане представляется актуальным. Смесь титановых гранул с порошком карбида вольфрама была использована для приготовления покрытий на титановом сплаве Ti6Al4V методом электроискровой обработки в гранулах. Были приготовлены три смеси гранул с содержанием карбида вольфрама 2.1, 4.1 и 6.0 об.\%. По данным рентгенофазового анализа установлено, что в составе покрытий наблюдались фазы: $\mathrm{WC}, \mathrm{W}_{2} \mathrm{C}, \mathrm{W}, \alpha \mathrm{Ti}$ и $\beta-(\mathrm{W}, \mathrm{Ti}) \mathrm{C}_{1-x}$. Карбиды $\mathrm{W}_{2} \mathrm{C},(\mathrm{W}, \mathrm{Ti}) \mathrm{C}_{1-x}$ и металлический вольфрам образовались в результате декарбидизации WC при его взаимодействии с расплавленным титаном в условиях электрического разряда. В микроструктуре покрытий наблюдались крупные включения карбида вольфрама, окруженные металлической Тi-W-C связкой. Согласно данным энергодисперсионного анализа концентрации 
вольфрама и углерода снижались при сканировании от поверхностных слоев покрытия к подложке. Средние значения микротвердости покрытий возрастали с 7.9 до 9.2 ГПа с увеличением концентрации порошка WC в смеси гранул. Средние значения коэффициентов трения покрытий находились в пределах $0.33-0.48$, что на $35 \pm 3 \%$ ниже, чем у сплава Ti6Al4V. Испытания на износ в режиме сухого трения при нагрузках 25 и $70 \mathrm{H}$, показали, что интенсивность изнашивания покрытий находилась в пределах от $0.38 \times 10^{-5}$ до $1.68 \times 10^{-5} \mathrm{Mm}^{3} / \mathrm{H}$. Лучшую износостойкость при различных нагрузках продемонстрировали покрытия, осажденные с добавлением 4.1 об.\% WC, которые позволяют повысить износостойкость сплава Ti6Al4V до 18 раз. Таким образом, показана перспективность электроискрового нанесения металлокерамических покрытий с повышенными механическими свойствами на титановый сплав используя порошок карбида вольфрама в смеси с титановыми гранулами.

Ключевые слова: сплав Ti6Al4V, карбид вольфрама, электроискровая обработка в гранулах, износостойкость, жаростойкость.

\section{1. Введение}

Титановые сплавы широко применяются в авиастроении, авиакосмической технике, химической промышленности, морской, судостроительной, оружейной и биомедицинской областях, благодаря их коррозионной стойкости, низкой плотности, высокой прочности, низкому модулю упругости и отсутствию цитотоксичности [1-2]. Однако слабая жаростойкость при температуре выше $500^{\circ} \mathrm{C}$, сравнительно низкая твердость и высокая вязкость, обуславливающие плохие трибологические свойства, являются характерными недостатками этих материалов [3]. Хорошо известно, что триботехнические характеристики титановых сплавов могут быть значительно улучшены путем нанесения металлокерамических (МК) покрытий, содержащих твердые керамические частицы $[4,5]$. Карбид вольфрама WC является подходящим материалом для создания MК покрытий на титановом сплаве, поскольку он устойчив к окислению, обладает высокими твердостью и прочностью, а также хорошо смачивается титаном [6,7].

Для нанесения MК покрытий из карбида вольфрама на сплав Ti6Al4V используют лазерную наплавку, газопламенное напыление, электроискровоелегирование (ЭИЛ) и др. [8-12]. Технология ЭИЛ основана на явлении электрической эрозии и переноса материала анода на поверхность катода-детали при протекании импульсных (искровых) разрядов в газовой среде [13]. Преимуществом ЭИЛ является простота и доступность оборудования, высокая адгезия покрытий за счет металлургического сплавления с материалом подложки. В предыдущих исследованиях было показано, что метод электроискровой обработки титанового сплава Ti6Al4V в смеси титановых гранул с порошком керамики позволяет создавать МК покрытия [14]. Такой способ ЭИЛ имеет ряд преимуществ, поскольку при традиционном ЭИЛ осаждении МК покрытий существуют ограничения по концентрации керамического компонента, вызван- ные высоким электрическим сопротивлением и низкой прочностью металлокерамических электродных материалов с высокой объемной долей керамики. Кроме того, он не требует дополнительных операций по подготовке МК электродов и позволяет наносить покрытия на детали с криволинейной поверхностью в автоматическом режиме. Поэтому цель настоящей работы заключалась в изучении структуры, износостойкости и жаростойкости покрытий, осажденных методом электроискровой обработки титанового сплава Ti6Al4V в смеси титановых гранул с различным количеством порошка карбида вольфрама (WC).

\section{2. Материалы и методы исследования}

Порошок карбида вольфрама в смеси с гранулами из титанового сплава ВТ1-00 использовались в качестве осаждаемого материала. Порошок WC (ТУ 6-09-03-360-78) имел чистоту 99\% и состоял из частиц сферической формы диаметром $1.1 \pm 0.3$ мкм. Гранулы из титанового сплава ВТ1-00 вырезались из проволоки диаметром $4 \pm 0.1$ мм на отрезки длиной $4 \pm 0.2$ мм. Гранулы и порошок в различных соотношениях (Табл. 1) засыпались в металлический контейнер, подсоединенный к положительному выводу генератора импульсов, и соответственно, гранулы выступали в качестве анода. Покрытия наносились на подложку (катод) из сплава Ti6Al4V в форме цилиндра диаметром 12 мм и высотой 10 мм. Подложка подключалась к отрицательному выводу генератора импульсов. Генератор разрядных импульсов IMES-40 выдавал импульсы тока прямоугольной формы амплитудой 110 А при напряжении 30 В, длительностью 100 мкс с частотой 1000 Гц. В рабочий объем контейнера подавался аргон со скоростью 10 л•мин ${ }^{-1}$ для предотвращения азотирования титана. Схема установки для электроискровой обработки нелокализованным электродом подробно описана в работе [15]. Обработка каждого образца продолжалась в течение 10 минут.

Табл. 1. Обозначение образцов, содержание карбида вольфрама в смеси гранул и толщина покрытий.

Table 1. Designation of samples, tungsten carbide content in the mixture of granules and the thickness of the coatings.

\begin{tabular}{|c|c|c|c|}
\hline $\begin{array}{c}\text { Обозначение образцов } \\
\text { Designation of samples }\end{array}$ & $\begin{array}{c}\text { Концентрация порошка, об.\% } \\
\text { Powder content, vol.\% }\end{array}$ & $\begin{array}{c}\text { Средняя толщина покрытий, мкм } \\
\text { Average thickness of coatings, } \mu \mathrm{m}\end{array}$ & $\begin{array}{c}\text { Шероховатость }\left(R_{a}\right), \text { мкм } \\
\text { Roughness }\left(R_{a}\right), \mu \mathrm{m}\end{array}$ \\
\hline WC2 & 2.1 & $15.6 \pm 7.6$ & $5.6 \pm 1.1$ \\
\hline WC4 & 4.1 & $16.6 \pm 7.4$ & $7.9 \pm 1.0$ \\
\hline WC6 & 6.0 & $19.2 \pm 4.8$ & $7.2 \pm 0.7$ \\
\hline
\end{tabular}


Структура покрытий исследовалась с применением рентгеновского дифрактометра ДРОН-7 в $\mathrm{Cu}-\mathrm{K}_{\alpha}$ излучении и растрового электронного микроскопа (СЭМ) Sigma 300 VP, оснащенного энергодисперсионным анализатором (ЭДС) INCA Energy. Шероховатость покрытий была измерена на профилометре TR200 (Китай). Твердость покрытий измерялась по методу Виккерса на микротвердомере ПМТ-3М при нагрузке $0.5 \mathrm{H}$. Износостойкость и коэффициент трения покрытий исследовались по процедуре ASTM G99 при сухом трении скольжения на скорости 0.47 мс $^{-1}$ при нагрузках 25 и $70 \mathrm{H}$. Испытание каждого образца продолжалось 10 минут. В качестве контртела использовались диски из быстрорежущей стали Р6М5 с твердостью 60 HRC. Износ измеряли гравиметрическим способом.

Циклические испытания на жаростойкость проводили в печи при температуре $900^{\circ} \mathrm{C}$ на воздухе. Во время испытания все образцы помещались в корундовый тигель для учета массы отслоившихся оксидов. Изменение массы всех образцов измеряли с использованием лабораторных весов с точностью 0.1 мг. Общее время тестирования составляло 100 часов.

\section{3. Результаты и обсуждение}

При прохождении электрического разряда между гранулой и подложкой происходит плавление металла и его полярный перенос на подложку [16]. Это сопровождается постепенным увеличением массы подложки с ростом времени обработки. Частицы карбида вольфрама, оказавшиеся в межэлектродном промежутке, в момент прохождения разряда смешивались с жидким титаном и фиксировались в покрытии. С ростом содержания порошка в смеси гранул возрастала величина привеса подложки от 2.85 до $6.33 \mathrm{mг} / \mathrm{cm}^{2}$ (Рис. 1а). Такое увеличение привеса катода можно объяснить участием диэлектрического порошка WC в инициировании разрядов. Присутствие частиц WC в межэлектродном промежутке способствует пучшему прерыванию электрического контакта в момент прохождения импульса, что повышает вероятность развития разрядов [13]. Неравномерное увеличение привеса подложки при увеличении содержания порошка в смеси гранул выше 4.1 об.\% может быть вызвано охрупчиванием покрытия из-за дефицита связующего и как следствие вызывать повышенную электрическую эрозию катода.

Рентгенофазовый анализ осажденных покрытий показал, что в их составе присутствуют фазы: $\alpha \mathrm{Ti}, \mathrm{W}$, $\mathrm{WC}, \mathrm{W}_{2}$ С и твердого раствора ГЦК $\beta$-(W, Ti) $\mathrm{C}_{1-x}$ (Рис. $\left.1 \mathrm{~b}\right)$. Формирование фаз $\mathrm{W}_{2} \mathrm{C}, \mathrm{W}$ в процессе электроискровой обработки сплава Ti6Al4V в среде титановых гранул и порошка карбида вольфрама происходит в результате его последовательного обезуглероживания при взаимодействии с титаном, согласно реакциям (1) и (2):

$$
\begin{gathered}
2 \mathrm{WC}+\mathrm{Ti}=\mathrm{TiC}+\mathrm{W}_{2} \mathrm{C} \\
\mathrm{WC}+\mathrm{Ti}=\mathrm{TiC}+\mathrm{W} .
\end{gathered}
$$

Вычисленный потенциал энергии Гиббса реакции (2) при температуре 2000 К составил -30.26 кДж/моль. Это свидетельствует о высокой реакционной активности титана при его высокотемпературном взаимодействии с карбидом вольфрама. При этом фаза (W,Ti) $\mathrm{C}_{1-x}$ является результатом внедрения вольфрама в решетку карбида титана [17], которое можно представить следующей схемой:

$$
x \mathrm{~W}+\mathrm{TiC}=\left[x \mathrm{~W}-\mathrm{Ti}_{-} \mathrm{C}_{1-x}\right]=(\mathrm{W}, \mathrm{Ti}) \mathrm{C}_{1-x} .
$$

Формирование фазы (W, Ti) $\mathrm{C}_{1-x}$ при ЭИЛ титанового сплава электродом WC-6\%Со наблюдалось в работе [18]. Как отмечается в работе [19], фаза (W, Ti) $\mathrm{C}_{1-x}$ обладает более высокими прочностью и твердостью по сравнению с карбидом титана.

Характерно, что с увеличением доли порошка WC в смеси гранул с 2.1 до 6.0 об.\% его концентрация в покрытии не повышалась выше 38 об.\%, но при этом, двукратно возрастала концентрация металлического вольфрама (Рис. 1b, Табл. 2). Это объясняется избытком титана поступающего в микрованну разряда из подложки, что интенсифицирует реакцию (2).

Изображения поперечного сечения покрытий WC2 и WC6 показаны на Рис. 2. С ростом содержания карбида вольфрама в смеси гранул средняя толщина покрытий возрастала слабо от 15.6 до 19.2 мкм (Табл. 1). В структуре покрытий наблюдались поры, возникновение которых, принято объяснять выделением газов в ходе протекания

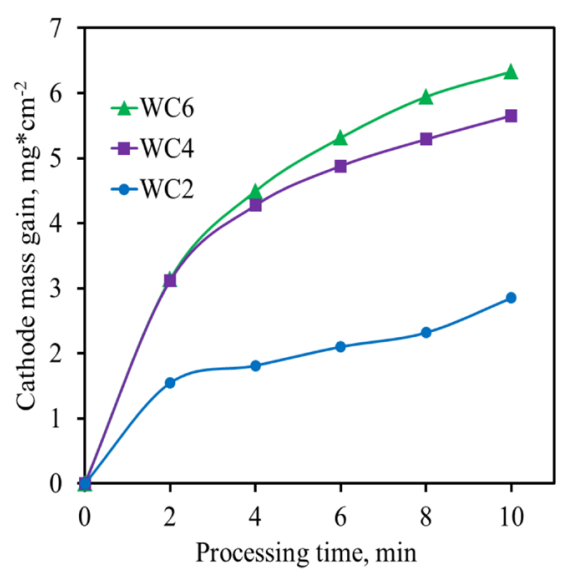

a

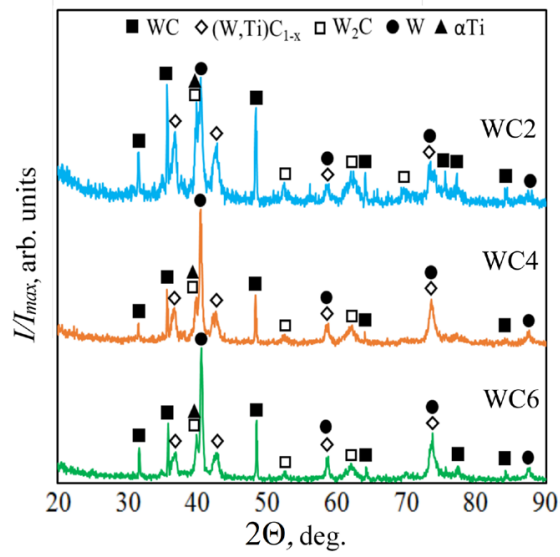

b

Рис. 1. (Color online) Прирост массы подложки как функция от времени осаждения (a) и рентгенограммы полученных покрытий (b).

Fig. 1. (Color onine) Mass gain of the substrate as a function of deposition time (a) and XRD patterns of resulted coatings (b). 
Табл. 2. Результаты полуколичественного рентгенофазового анализа покрытий.

Table 2. Results of semi-quantitative X-ray phase analysis of coatings.

\begin{tabular}{|c|c|c|c|c|c|}
\hline \multirow{2}{*}{$\begin{array}{c}\text { Образцы } \\
\text { Specimens }\end{array}$} & \multicolumn{5}{|c|}{ Содержание фаз, об.\% / Phases content, vol.\% } \\
\cline { 2 - 6 } & $\alpha \mathrm{Ti}$ & $\mathrm{W}$ & $\mathrm{WC}$ & $\mathrm{W}_{2} \mathrm{C}$ & 12.8 \\
\hline WC2 & 14.6 & 22.5 & 37.7 & 14.4 & 12.4 \\
\hline WC4 & 11.8 & 40.3 & 24 & 8.7 & 9.6 \\
\hline WC6 & 9 & 43.3 & 28.1 & 11 \\
\hline
\end{tabular}

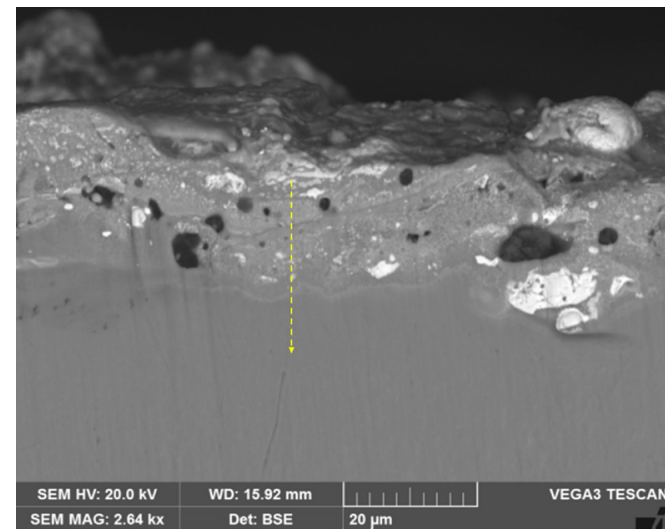

a

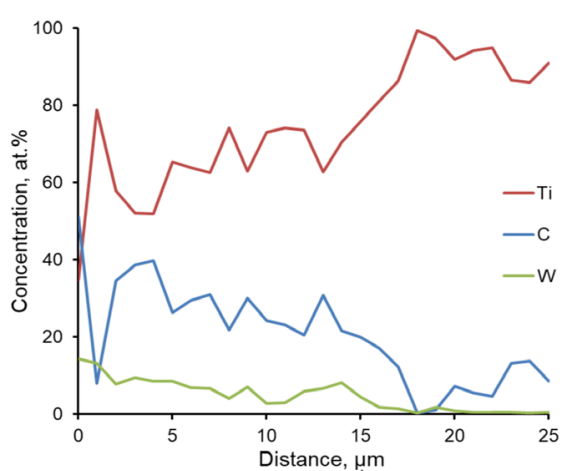

c

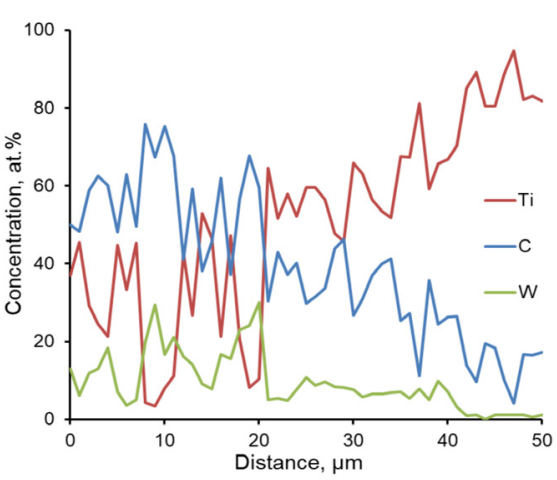

d

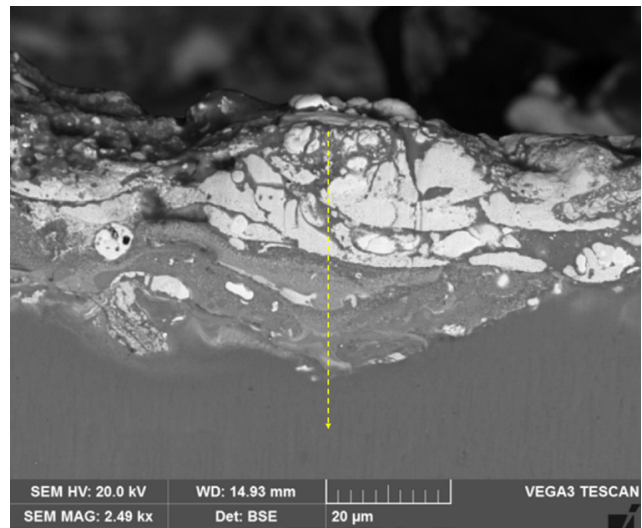

b

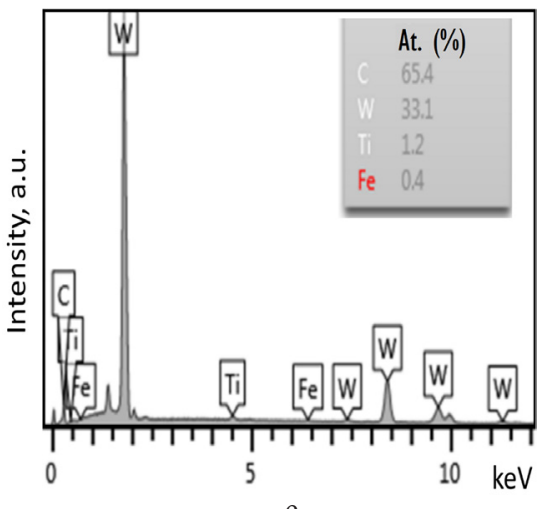

$\mathrm{e}$

Pис. 2. (Color online) СЭМ изображения поперечного сечения покрытий: WC2 (a) и WC6 (b); и распределение элементов по сечению соответствующих покрытий, согласно данным ЭДС анализа (c), (d); типичные ЭДС спектры светлых включений (е). Пунктирная линия обозначает направление сканирования.

Fig. 2. (Color online) SEM images of the cross section of the coatings WC2 (a) and WC6 (b); and the distribution of elements over the crosssection of the respective coatings according to EDS data (c), (d); typical EDS spectra of bright inclusions (e). The dashed line indicates the scanning direction.

разрядов [20]. Осажденные покрытия не имели четкой границы с подложкой и продольных трещин, что может свидетельствовать о хорошей адгезии осажденного слоя с подложкой. Отсутствие четкой границы покрытия с подложкой объясняется интенсивным конвективным перемешиванием перенесенного материала с расплавом металла подложки в микрованне разряда. Следы конвективных потоков отчетливо видны в слоях покрытий, прилегающих к подложке (Рис. $2 \mathrm{a}, \mathrm{b})$. Распределения элементов по глубине покрытий показаны на Рис. 2 c, d. При переходе от поверхности покрытия к подложке концентрация титана постепенно возрастала, а содержание вольфрама и углерода снижалась. На фотографиях покрытий (Рис. $2 \mathrm{a}, \mathrm{b}$ ) в режиме обратно отраженных электронов отчетливо видны белые зерна, вкрапленные в серую матрицу. По данным МРС анализа в составе белых включений преобладают вольфрам и углерод (Рис. $2 \mathrm{a}, \mathrm{b})$, что позволяет идентифицировать их как карбида вольфрама. Большинство включений имели неправильную округлую форму, также как и исходные частицы порошка WC. Включения имели диаметр от 1 до 25 мкм, при этом наиболее крупные из них имели внутренние границы между более мелкими областями гомогенности. Вероятно, крупные включения WC сформировались в результате попадания в область разряда крупных агломератов частиц исходного порошка карбида вольфрама. В связи с этим следует зафиксировать, что крупные включения неправильной формы это агломераты частиц исходного порошка WC перенесенные в покрытие в твердой фазе и не подвергшиеся значительному плавлению и обезуглероживанию. Шероховатость покрытий, по критерию $R_{a}$, находилась в диапазоне от 5 до 8 мкм, что не выше чем у покрытий полученных традиционным ЭИЛ (Табл. 1).

Средние значения твердости покрытий находилась в диапазоне от 7.9 до 9.2 ГПа (Рис. 3 а). Твердость покры- 
тий WC4 и WC6, с учетом доверительных интервалов, была примерно одинаковая $\approx 9$ ГПа, что в 3 раза выше, чем у сплава Ti6Al4V (2.4 0.5 ГПа). Коэффициенты трения покрытий находились в диапазоне от 0.3 до 0.5 . (Рис. 3 b). При этом, наиболее низкие коэффициенты трения наблюдались у покрытий WC4 (0.38) при нагрузке $25 \mathrm{H}$ и WC6 (0.33) при $70 \mathrm{H}$, что на $35 \pm 3 \%$ ниже, чем у сплава Ti6Al4V. На Рис. 3 b хорошо видно, что в случае сплава Ti6Al4V наблюдается более высокий уровень шума по сравнению с покрытиями. Высокая девиация коэффициента трения отражает флуктуацию силы трения, которая может быть вызвана деформацией шероховатостей или их адгезионным взаимодействием с сопряженной поверхностью, а также отделением частиц износа [21-22]. Кроме того, к резким колебаниям силы трения может приводить разрушение и повторное формирование трибооксидного слоя [23-24].

Результаты испытания сплава Ti6Al4V и осажденных покрытий на износ в режиме сухого скольжения показаны на Рис. 3 с. Из него следует, что интенсивность изнашивания сплава Ti6Al4V была почти в 2 раза выше при нагрузке $25 \mathrm{H}$, по сравнению с $70 \mathrm{H}$. Средние значения интенсивности изнашивания покрытий изменялись немонотонно с ростом объемной доли порошка карбида вольфрама в смеси гранул. Так при обеих нагрузках минимальная интенсивность изнашивания покрытий наблюдалась для покрытия WC4. Более низкая износостойкость покрытия WC6 объясняется частичным выкрашиванием из-за большой концентрации зерен WC, т.е. в данном случае начинает проявляться дефицит связующего. Кроме того, в более толстослойных покрытиях выше концентрация дефектов, которые способствуют более интенсивному удалению фрагментов образца вместе с материалом контртела. Таким образом, концентрация порошка WC 4.1 об.\% в смеси гранул является оптимальной, поскольку в соответствующем покрытии соблюдается наилучший баланс связующей матрицы и армирующей фазы. В целом интенсивность износа полученных покрытий была от 8 до 18 раз ниже по сравнению со сплавом Ti6Al4V. Таким образом, применение электроискровой обработки сплава Ti6Al4V в среде титановых гранул с порошком карбида вольфрама позволяет снизить и стабилизировать силу трения, а также кардинально сократить износ титановых изделий.

На Рис. $3 \mathrm{~d}$ показано изменение массы образцов с покрытиями и сплава Ti6Al4V с ростом времени выдержки при температуре $900^{\circ} \mathrm{C}$. Привес образцов обусловлен фиксацией кислорода на поверхности образцов в виде

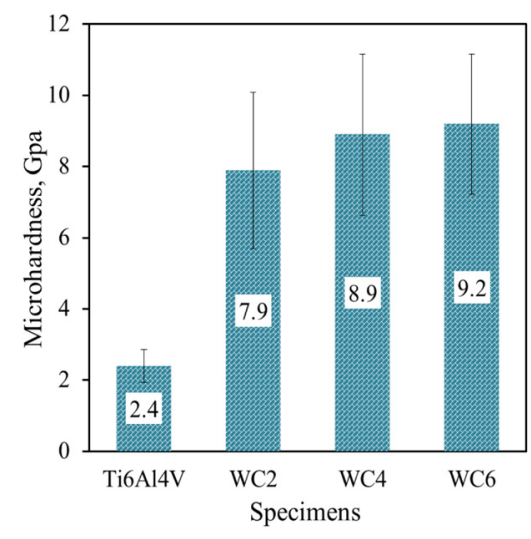

a

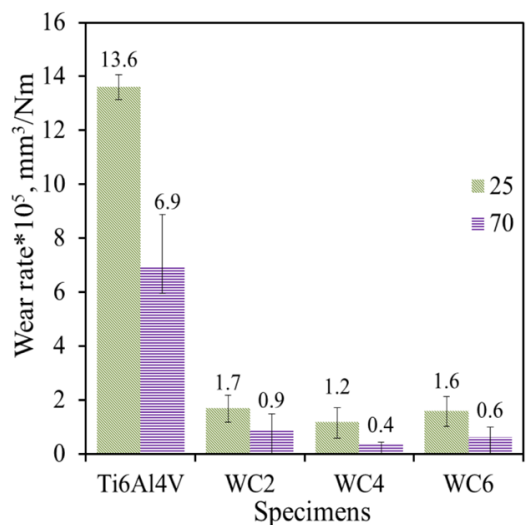

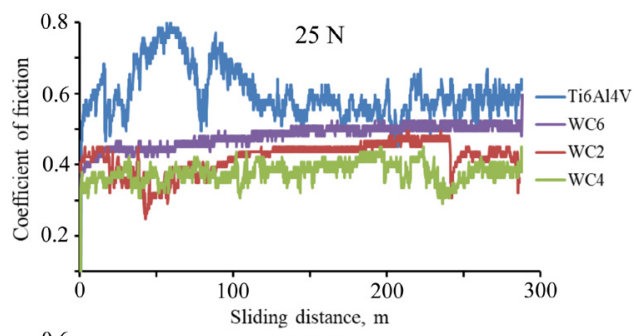

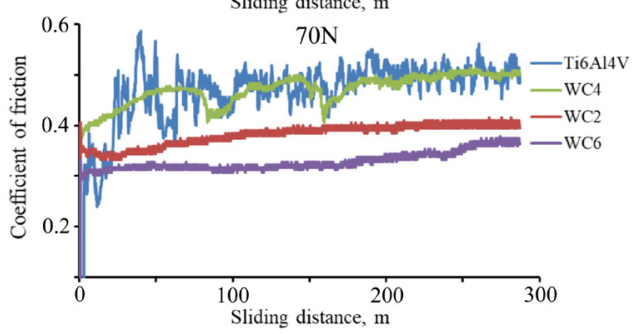

b

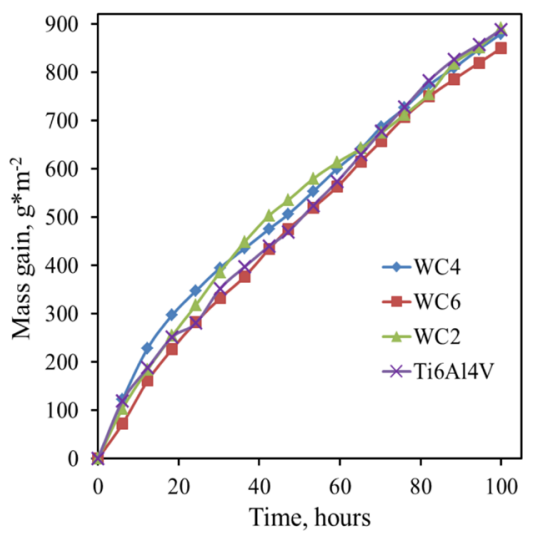

d

Pис. 3. (Color online) Твердость (a), коэффициент трения (b), интенсивность изнашивания при нагрузках 25 и 70 Н (c) и жаростойкость покрытий при $900^{\circ} \mathrm{C}(\mathrm{d})$ по сравнению со сплавом Ti6Al4V.

Fig. 3. (Color online) Hardness (a), friction coefficient (b), wear rate at loads of 25 and $70 \mathrm{~N}$ (c) and oxidation resistance of the coatings at $900^{\circ} \mathrm{C}$ (d) compared to Ti6Al4V alloy. 
оксидного слоя из рутила [25]. По достижении $\approx 20$ ч оксидный слой начал замедлять процесс диффузии кислорода к металлу, что отразилось в снижении скорости привеса образцов. Кривые привеса всех образцов и сплава Ti6Al4V после 100 ч испытания можно трактовать как отсутствие защитного эффекта покрытий на основе карбида вольфрама от высокотемпературной коррозии.

\section{4. Выводы}

Были приготовлены покрытия на титановом сплаве Ti6Al4V методом электроискровой обработки в смеси титановых гранул с порошком карбида вольфрама. В составе покрытий методом рентгенофазового анализа были обнаружены карбиды вольфрама: WC, $\mathrm{W}_{2} \mathrm{C}$, карбид $(\mathrm{W}, \mathrm{Ti}) \mathrm{C}_{1-x}$, а также вольфрам и титан. C увеличением концентрации порошка WC в смеси гранул с 2.1 до 6.0 об.\% повышался привес катода и средняя толщина покрытий. Микротвердость покрытий также слабо возрастала с 7.9 до 9.2 ГПа. Средние значения коэффициентов трения покрытий находились в пределах $0.33-0.48$, что на $35 \pm 3 \%$ ниже, чем у сплава Ti6Al4V. Износостойкость покрытий была от 8 до 18 раз выше, чем у сплава Ti6Al4V. Циклические испытания образцов на жаростойкость при $900^{\circ} \mathrm{C}$ показали, что покрытия на основе карбида вольфрама не улучшают барьерные свойства сплава Ti6Al4V. Таким образом, показана перспективность электроискрового нанесения металлокерамических покрытий с повышенными механическими свойствами на титановый сплав используя порошок карбида вольфрама в смеси с титановыми гранулами.

\section{Литература/References}

1. F. Weng, C. Chen, H.Yu. Mater. Des. 58, 412 (2014). Crossref

2. M. A. Cuddihy, A. Stapleton, S. Williams, F. P. E. Dunne. Inter. J. Fatigue. 97, 177 (2017). Crossref

3. B. Ganesh, W. Sha, N. Ramanaiah, A. Krishnaiah. Mater. Des. 56, 480 (2014). Crossref

4. X. Li, B. Tang, J. Pan, D. Liu, Z. Xu. J. Mater. Sci. Technol. 19, 291 (2003).

5. H. Liu, X. Zhang, Y. Jiang, R. Zhou. J. Alloys Compd. 670, 268 (2016). $\underline{\text { Crossref }}$
6. M. Erfanmanesh, H. Abdollah-Pour, H. MohammadianSemnani, R. Shoja-Razavi. Ceramics International. 44, 12805 (2018). $\underline{\text { Crossref }}$

7. L.-J. Yang, S.-P. Wang, P. Wang, H. Li, H.-Y. Yang, Y.-S. Ye, Z.-X. Li. J. Iron Steel Res. Int. 27, 228 (2020). Crossref

8. W. Pang, H. C. Man, T. M. Yue. Mater. Sci. Eng. A. 390, 144 (2005). Crossref

9. M.S. Mahdipoor, F. Tarasi, C. Moreau, A. Dolatabadi, M. Medraj. Wear. 330 - 331, 338 (2015). Crossref

10. H. Guo, Z. Tian, Y. Huang, H. Yang. J. Rus. Laser Res. 36 (1), 48 (2015). Crossref

11. O. N. Celik. Appl. Surf. Sci. 274, 334 (2013). Crossref

12. R. J. Wang, Y.Y. Qian, J.Liu. Appl. Surf. Sci. 228, 405 (2004). Crossref

13. V.V. Mikhailov, A.E. Gitlevich, A.I. Mikhailyuk, A.D. Verkhoturov, A.V. Belyakov, L.A. Konevtsov. Surface Engineering and Applied Electrochemistry. 49 (5), 373 (2013). Crossref

14. A. A. Burkov, M. A. Kulik. Letters on Materials. 9 (2), 243 (2019). (in Russian) [А. А. Бурков, М. А. Кулик. Письма о материалах. 9 (2), 243 (2019).] Crossref

15. A. A. Burkov, P. G. Chigrin. Surf. Coat. Technol. 351, 68 (2018). Crossref

16. O.P. Umanskyi, M.S. Storozhenko, V.B. Tarelnyk, O. Y. Koval, Y.V. Gubin, N.V. Tarelnyk, T.V. Kurinna. Powder Metallurgy and Metal Ceramics. 59, 57 (2020). Crossref

17. J. Lin, Y. Hao, L. Luo, M. Zhao, Q. Xu, X. Zan, X. Zhu, Y.Wu. J. Alloys Compd. 732, 871 (2018). Crossref

18. K.A. Kuptsov, A.N. Sheveyko, E.I. Zamulaeva, D. A. Sidorenko, D. V. Shtansky. Mater. Des. 167, 107645 (2019). Crossref

19. J. Jung, S. Kang. Scripta Mater. 56, 561 (2007). Crossref

20. M. Salmaliyan, F. Malek Ghaeni, M. Ebrahimnia. Surf. Coat. Technol. 321, 81 (2017). Crossref

21. G. X. Chen, Z. R. Zhou, P. Kapsa, L. Vincent. Wear. 253, 411 (2002). Crossref

22. Y. Liu, Z. Zheng, C. Yang, D. Zhu, W. Chen. Tribol. Lett. 65, 39 (2017). rossref

23. F. H. Stott, M.P. Jordan. Wear. 250-251, 391 (2001). Crossref

24. M.X. Wei, S. Q. Wang, L. Wang, X. H. Cui. Tribol. Trans. 54, 840 (2011). Crossref

25. A. A. Burkov. Letters on Materials. 5 (4), 371 (2015). (in Russian) [А. А. Бурков. Письма о материалах. 5 (4), 371 (2015).] Crossref 